\title{
Presto! In the Groove!
}

\author{
Darryl D. Draper \\ Northern Illinois University
}

C

lark and Mayer's (Mayer, 2005) modality principle stated the "there is considerable evidence that presenting words in audio, rather than on-screen text, results in significant learning gains." (p. 99) The advantage of utilizing visuals and audio allows the division of incoming information into two separate channels: words spoken in the audio channel and text or graphics in the visual channel. Research suggests that the use of audio narration to replace onscreen text to complement complex visual illustrations is likely to avoid the overloading of the visual channel in an individual's working memory. (Mousavi, Low, \& Sweller, 1995). This instructional strategy is highly effective when the learner is presented with complex processes, or in the animation of graphics to facilitate the knowledge acquisition process.

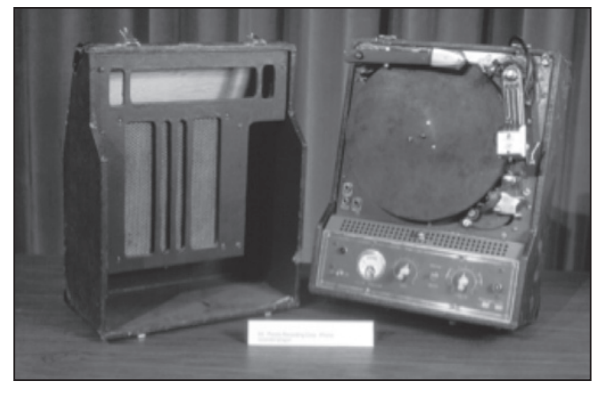

The Presto Model Recorder

The Presto Model Recorder was produced between 1934 and 1956, with an initial selling price of less than $\$ 300$ U.S. (www.televar.com) Presto Recording Corporation is credited for the development of the first cellulose-recording disc and recording equipment. The disc's unique soft cellulose coating allowed the recording head to cut a groove on the surface of the disc allowing for instantaneous sound recording equipment. During the 1930's Presto recording equipment was being installed in radio stations across the U.S. NBC and CBS were the first to adopt this technology in their recording studios. A form of this technology remains in use today to prepare master discs for analog records. (www.telvar.com)

\section{References}

Clark. R. C., \& Mayer, R.E., (2008). E-learning and the science of instruction. San Francisco, CA: Pfeiffer.

Lee and Lida Cochran AECT Archives.

(1999). Phono Recorder/Player. DeKalb, Illinois: Blackwell Museum of Education, Northern Illinois University. Accessed January 25, 2012. http://www.cedu. niu.edu/blackwell/multimedia/images/ JPEGS/SLIDE063.JPG

Graves, A.C. (2009). The presto history page. Retrieved from http://www.televar.com/ grshome/Presto.htm

Mayer, R.E. (2005). Principles for managing essential processing in multimedia learning: Segmenting, pretraining, and modality principles. The Cambridge handbook for multimedia learning ( $p$ p. 147-158). New York: Cambridge University Press.

Mousavi, S.Y., Low, R. \& Sweller, J., (1995). Reducing cognitive load by mixing auditory and visual presentation modes. Journal of Educational Psychology, 87, 319-334. 